\title{
Effects of goal-setting skills on students'academic performance in english language in Enugu Nigeria
}

\author{
Abe, Iyabo Idowu ${ }^{1, *}$, Ilogu, Guy Chibuzoh², Madueke, Ify Louisa ${ }^{3}$ \\ ${ }^{1}$ Department of Educational Foundations, University of Lagos, Nigeria, \{iabe@unilag.edu.ng\} \\ 2Department of Educational Foundations, University of Lagos, Nigeria \{gilogu@unilag.edu.ng\} \\ ${ }^{3}$ Yaba College of Technology \{bigorange_24@yahoo.com\}
}

Received on 22 April 2013; revised on 23 April 2013; accepted on 16 July 2013; published on 15 July 2013

DOI: 10.7821/naer.3.2.93-99

\begin{abstract}
The study investigated the effectiveness of goal-setting skills among Senior Secondary II students' academic performance in English language in Enugu Metropolis, Enugu state, Nigeria. Quasi-experimental pre-test, post-test control group design was adopted for the study. The initial sample was 147 participants (male and female) Senior Secondary School II students drawn from two public schools in Enugu zone of Enugu Metropolis. The final sample for the intervention consisted of 80 participants. This sample satisfied the condition for selection from the baseline data. Two research hypotheses were formulated and tested at 0.05 level of significance. Data generated were analyzed using the mean, standard deviation and t-test statistical method. The findings showed that performance in English language was enhanced among participants exposed to goal-setting intervention compared to those in the control group. The study also showed that there is a significant gender difference in students' performance with female participants recording a higher mean score than males. Parental level of education was also found to be related to performance in English Language. Based on the findings, goal-setting intervention was recommended as a strategy to enhancing students' academic performance particularly in English Language.
\end{abstract}

KEYWORDS: GOAL SETTING, ACADEMIC PERFORMANCE, ENGLISH LANGUAGE, STUDENT, EXAMINATIONS

\section{INTRODUCTION}

\subsection{Background to the study}

English is used at all levels of education throughout the country as a subject of study and a medium of instruction. It is also the national language for politics, governance and commerce. Unfortunately, students' performance in the subject continues to be poor and this has been attributed to other factors. Such factors include parental variables, teachers' teaching styles and learner's environment (Ikegbunam, 1989). There is therefore the need to

\footnotetext{
*To whom correspondence should be addressed:

Iyabo Idowu Abe

University of Lagos, Faculty of Education

Akoka, Yaba

Lagos, Nigeria
}

investigate this national problem from other perspectives. Researchers should look at students' personal perspectives; perhaps goal setting as a teaching-learning strategy would enhance their performance in the subject irrespective of gender. This is the focus of the study. Locke and Latham (1990) asserted that goals motivate individuals to exert extra effort, persist and focus attention on relevant task features. Specific goals also serve as a guide to develop strategies that will help students accomplish academic tasks in time. Basically, at the initial stage of a learning activity, students have such goals as acquiring skills and knowledge, finishing work and making good grades. During the activity, students usually observe, judge and react to their perceptions of goal progress so that when a commitment is made, there would be the basis for comparison between their performance and the targeted goals. Such self-evaluations of progress raise and sustain motivation; while a perceived discrepancy between performance and the goal may create dissatisfaction resulting in putting in more efforts. Hence goalsetting is necessary in order to identify what one should be doing, how he should be doing it, how long it should take and the things required for its accomplishment. It is important for students to set SMART goals where $\mathrm{S}$ stands for specific, $\mathrm{M}$ measurable, $\mathrm{A}$ - attainable, $\mathrm{R}$ - reliable and $\mathrm{T}$ - timely. In addition, such skills and possession of special abilities as determination, interest, self-motivation, hard work, persistence and being focused, all of which are intrinsic to goal setting are likely to be developed, thus leading to improved academic performance. It helps to initiate students' self appraisals as learners monitor their own progress towards meeting clear endpoints of their efforts in English Language particularly in continuous writing.

\subsection{Statement of the Problem}

Mass failure of students in English language has been a source of concern to parents, students, teachers and the society at large. The mass failure has been attributed to teachers' methodology, non availability of teaching materials and parental factors (Ikegbunam, 1989). All of these appeared to have been investigated yet the problems seem to have remained persistent going by the recurring mass failure in English language external examinations in the state.

If performance in English language continues to be poor as it is now, Nigeria may never attain her goal of developing modern 
technology using her own human resources and may have to continue to rely on manpower from other countries. Therefore, there is the need for students to perform well to achieve the required degree of accuracy and utilization of English Language for both personal and national development. Attempts at improving performance have focused on parents, teachers and other school factors. There is the need to look at the students themselves because we believe that they can determine their own success or failure by their disposition and efforts. It is assumed as stated earlier that if learning objectives are broken down into small short term goals, students' are likely to be motivated as each small goal is achieved, ultimately leading to better performance in English language.

\subsection{Theoretical Framework and a Review of Related Studies}

The present study is anchored on goal-setting theory (Locke \& Latham, 1990) and language acquisition theory (Chomsky, 1975; Ellis (in press)).

Goal-setting theory states that the process of setting goals and targets allows one to be focused to provide a sense of direction and enables one to achieve aim without distraction. It also builds self-confidence and improves performance as one recognizes the ability and competence in achieving set goals. Goals represent concretized or focused needs. In other words, if you intend to do something, you will tend to plan how to do it. According to the goal-setting theorists, two conditions must be met before goals can positively influence performance. First, the individual must be aware of the goal and its objectives. Second, the individual must accept the goal as something he or she is willing to work for (Locke \& Latham 1990). This theory is therefore relevant to the study because it emphasizes that students of English Language must be focused and have goals in order to have a direction, which will guide them to achieve these goals. Similarly, the language acquisition theory by Chomsky (1975) states that, children are born with an innate propensity for language acquisition, which makes the task of learning a second language easier than it would otherwise be. The human brain according to Chomsky is ready naturally for language in the sense that when children are exposed to speech, certain general principles for discovering or structuring language automatically begin to operate. He originally theorized that children were born with a hard wired, Language Acquisition Device (LAD) in their brains. This idea was further expanded to Universal Grammar, a set of inert principles and adjustable parameters that are common to all human languages. The child exploits its LAD to make sense of the utterances heard around him.

Also from the psycholinguistic point of view, Second language acquisition is construction -based, rational, exemplardriven, emergent and dialectic. According to Ellis (In press), a fundamental tenet is that we children or even adults learn language in much the same way as we learn everything else, the cognitive language system is special because the problem of representing and sharing meanings across a serial speed stream is unique to language, both the process of learning are cut of the same cloth as the rest of human cognition. Hence language acquisition is governed by general laws of human learning both associative and cognitive while from the socio-cultural perspectives. Ellis (1997) reasons that individuals who are motivated to integrate both linguistic and non-linguistic outcomes of the learning experience will attain a higher degree of L2 proficiency and more desirable attitudes.
The relevance of these theories to the study is based on inducing students' responses with the help of goal-setting skills and exercises to enhance performance in English.

Researchers in developmental psychology have always been interested in the effect of social context on children's learning and development (O’Donnel, 2006) leading to increasing research focus on intervention programmes that can benefit students. Access to goal-setting skills is among the most prominent of such interventions (Ridley, 1992). According to Ilogu (2005), goals are specific targets an individual is consciously trying to attain particularly in relation to future objectives such as equity and expectancy. Goals direct behaviour and provide guidelines for how much effort to be put into work for an expected result. In other words, people are likely to perform better if they are convinced they will be rewarded appropriately. Likewise students will study better if they believe that promotion, recognition or reward will follow their performance without delay. In support of this, Barry (2007) stated that young people will work harder, longer and will commit more willingly to tasks where accomplishment is certain to be an outcome. Also, Brown and Latham (2000) indicated that in conditions where individuals set specific, difficult but realistic goals, performance is higher than when individuals are just asked to do their best without specific goals.

Schunk (1993) for example found that participation in goalsetting by sixth graders enhances achievement outcomes which have confirmed the usability, and fruitfulness of goal-setting. In a study by Hopman and Glynn (1989), the writing output of 13year-old boys with academic difficulties was increased by asking them to set a performance goal for the number of words they would include in the essays. Similarly, Hall (1990) reported that college students in remedial writing classes increased the amount of journal writing completed when a goal was set for the number of lines to be written each day. Other conditions and characteristics that also influence students' attributions about successes or failures which should include past experiences, family, social class, level of need, achievement, persistence of behaviour, task characteristics, individual predispositions and model characteristics.

The importance of goal-setting is especially apparent in the composing behaviour of professional writers. Lamb (1997) found out that when writing a book on the major candidates in 1988 presidential campaign, Crame established a goal from the start to write "a real human story about these guys". Other writers, who have proved the efficacy of good writing, were Hemingway and Trollope, as quoted by Burgess (1991) who stated that goal-setting helped to regulate their writing habits and output. Burgess, the novelist, equally set a goal to write 2000 words a day when he was incorrectly told at the age of 42 that he would die within a year. He published five books in the space of a year. However there is evidence that even when children are taught by the same teacher, sitting in the same class room, reading the same text book, listening to the same teacher; boys and girls perceive things in different ways and perform differently (Sadker \& Sadker, 1994). Smith (2007) in support of the above stated that girls perform better than boys in languages, while many male students prefer number and numeration, algebra process and construction. Girls outperform boys in national tests. Girls are also higher achievers than boys at General Certificate for Secondary Examination (GCSE) level (Smith, 2003). There is also a general tendency to associate poor academic performance with boys (Jones \& Myhill 2004). Therefore girls are said to perform better than boys in English 
Language following the fact that there is a relationship between learners' gender and second language performance.

\subsection{Purpose of the Study}

The purpose of the research was to:

1. Investigate the difference in post-test scores on English Language of participants exposed to goal-setting skills and the control group.

2. To study gender difference in post-test scores on English Language of participants exposed to goal-setting skills.

\subsection{Research Questions}

The following research questions guided the study:

1. Is there any difference in the post-test scores on English Language among participants exposed to goal-setting skills and control group?

2. Is there any gender difference in the post-test scores on English Language among participants exposed to goalsetting skills.

\subsection{Research Hypotheses}

The following hypotheses were formulated to guide the study:

1. There will be no significant difference in the post-test scores of English Language among participants exposed to goal-setting skills and control group.

2. There will no significant gender difference in the posttest scores of English Language among participants exposed to goal-setting skill.

\subsection{Scope of the Study}

The study was limited to Senior Secondary two students from two secondary schools from one educational zone in Enugu State of Nigeria. The emphasis was on the effects of goal-setting skills on students' academic performance in English language in Enugu metropolis. The variables considered were academic performance in English language, goal-setting skills and gender.

\section{METHODOLOGY}

\subsection{Research Design}

Quasi experimental design was used since the study involved human behaviour. This design merely requires that participants are tested with the same instruments before and after training intervention.

\section{$2.2 \quad$ Research Setting}

The study area was Enugu state, Nigeria. Enugu is the capital city of Enugu state. It is located in the South Eastern geopolitical section of Nigeria in West Africa. It is bound by Ebonyi State in the East, Abia State in the West, Benue state in the North Anambra State in the South. It is largely populated by members of the Igbo ethnic group, one of the largest ethnic groups in Nigeria. Enugu was formerly the capital of Eastern Nigeria with a lot of industries. Like many other states, there are records of high failure rates in public examinations such as Senior Secondary Certificate Examination (SSCE) and National Examination Council (NECO).

\subsection{Sample and Sampling Procedure}

The sampling procedure that was employed for this study was multistage sampling technique. The two schools were selected from Enugu eastern and northern zones. Using the simple random sampling method (hat and draw) two public secondary schools were selected from 17 public secondary schools in four Local Government Areas. The schools were:

1. Day Secondary School, Independence layout, Enugu North.

2. Annunciation Secondary School, Enugu East.

Out of a total of seventy seven students at Day Secondary School Independence Layout Enugu, forty students were selected. At the Annunciation Secondary School, Enugu, which is the control group, forty students were selected out of a total of seventy students. A total of eighty students were selected from 147 participants comprising both male and female students in the intact classes used. The baseline assessment was done using Goal-Setting Procedure (GSP) and Academic Performance Tests in English Language (APTEL). The schools were randomly assigned to treatment conditions and control group: (a) School 1 - Goal-setting skills; (b) School 2 - Control group

To avoid contamination, the students were treated in their various schools and their classrooms were used as locations for the study.

\subsection{Instrumentation}

Two research instruments were used to collect relevant data for this study.

1. Goal-Setting Procedure Instrument (GSP) with student's personal data in its first part.

2. Achievement Tests in English language (ATEL)

\subsubsection{Goal-Setting Procedure Instrument (GSPI)}

Researcher prepared 20 items on Goal-Setting Procedure adapted from Self-Efficacy Scale by Sherer et al (1982). It was made culture-fair by altering some of the items on the original questionnaire and including some items on goal-setting skills. It has a mean alpha of 0.86 with a good construct validity by correlating significantly with interpersonal competency scale and Rosenberg Self-esteem scale. The instrument was used to assess students' goal setting abilities; 12 positive statements and eight negative statements. Examples of these changes include: 'I like to grow house plants' was changed to 'I fix time limit to achieve my goal'; 'I like to cook' was changed to 'I solve most problems by motivating myself. Direct scoring for positive statements was $1-4(A=1, B=2, C=3, D=4)$ while reverse scoring for negative statements was $4-1$. The overall GSP score ranges from 20 - 80; the higher the score the higher the goal-setting ability. The instrument was revalidated after altering a few items (Figure 1). 
Figure 1. Sample of question under this instrument

\begin{tabular}{|c|c|c|c|c|c|}
\hline $\mathbf{S} / \mathbf{N}$ & Variable & 4 & 3 & 2 & 1 \\
\hline 1 & $\begin{array}{l}\text { When I have something unpleasant to do, } \\
\text { I stick to it until I finish it }\end{array}$ & & & & \\
\hline 2 & $\begin{array}{l}\text { When unexpected problems occur, I do } \\
\text { not handle them }\end{array}$ & & & & \\
\hline 3 & Failure just makes me try harder & & & & \\
\hline 4 & $\begin{array}{l}\text { Once I get a goal I don't give up until I } \\
\text { achieve it }\end{array}$ & & & & \\
\hline
\end{tabular}

\subsubsection{Academic Performance Tests in English language (ATEL)}

A 100 - item achievement tests covering all areas of English Language was prepared and used by the researcher. The respondents answered the questions according to the various instructions for each part. The instrument was used to identify students with poor, average and high performance in English language. The ATEL was constructed using a test blue print or table of specification to establish its content validity. The blue print is a test plan aimed at systematic coverage of the course contents and instructional objectives. Samples of questions include:

a) The ATEL was carefully planned to reflect and emphasize students' knowledge, comprehension and application (Table 1).

b) Sample of the content of the instruments include:

(Part I)

Choose the one that is nearly opposite in meaning from the Underlined word and fill in the gap

1. The handsome profit from her fish business made Mrs. Uba stop complaining about her husband's.......salary.

(a).Ugly (b).Meagre (c).Modest (d).Lowly

2. Chief Osa prefers fame in the village to...... in the city.

(a).Neglect (b).Ignorance (c).Poverty (d).Obscurity

(Part II)

Instruction: From the word lettered A-D, choose the word that best completes of the following sentences.

1. One very important aspect of human relationships is .....trust.

(a).Communal (b).Individual (c).Mutual (d).Personal

2. The two were performed........and we were able to finish early.
(a).Alternatively (b).Simultaneously (c).Consecutively (d).Separately

(Part III )

After each of the following sentence, a list of possible interpretations is given. Choose the interpretation that you consider most appropriate for each sentence.

1. James and Henry were at daggers drawn when I knew them. This means

(a).Were always angry with each other (b).Always wore dagger (c).Were good at drawing dagger (d).Were fighting everybody

2. Whenever my cousin comes to realize that I am telling the truth, she will eat humble pie. This means that my cousin will
(a).Respect me ashamed

(Part IV)

In each of the following questions, the main stress is indicated by writing syllable on which it occurs in capital letters. From the words lettered A-D, choose the one that has the correct stress.

1. democratic

(a).DE-mo-cra-tic (b).de-MO-cra-tic (c).de-mo-CRAtic (d).de-mo-cra-TIC

2. competitor

(a).COM-pet-i-tor (b).com-PET-i-tor (c).com-pet-I-tor

(d).com-pet-i-Tor

\subsection{Validation and Reliability Test of Instruments}

Validation and reliability co-efficient of the instruments were established using test-retest method. It was also used to identify the problems with the instruments and to make the instrument culture fair. Sixteen male and sixteen female students that are not in the group for the main study were randomly selected for the pilot study. Content validity of instruments was achieved through submitting items to the researcher's supervisors, two experts in English Language and lecturers in the Department of Educational Foundations of the University of Lagos who are also experts in Measurement and Evaluation. Their structural ideas formed the basis for the modification of the questionnaire. Results showed that the instrument was appropriate for the study with concurrent validity of .69 for English Language and .62 for Goal-Setting. Thereafter, the reliability was established through pilot testing and the test re-test reliability obtained was .74 for English Language achievement test and .61 for Goal-Setting, confirming the instruments as being stable.

Table 1. Table of Specification for the English Language Test

\begin{tabular}{|c|c|c|c|c|c|}
\hline Behaviour /Content & $100 \%$ & $\begin{array}{c}\text { Knowledge } \\
45 \% \\
\end{array}$ & $\begin{array}{c}\text { Comprehension } \\
35 \% \\
\end{array}$ & $\begin{array}{c}\text { Application } \\
20 \% \\
\end{array}$ & $100 \%$ \\
\hline Writing & 40 & 18 & 14 & 8 & 40 \\
\hline Comprehension & 10 & 4 & 4 & 2 & 10 \\
\hline Summary & 20 & 9 & 7 & 4 & 20 \\
\hline Synonyms/Antonyms & 10 & 5 & 3 & 2 & 10 \\
\hline Lexis \& Structure & 10 & 4 & 4 & 2 & 10 \\
\hline Test of Orals & 10 & 5 & 3 & 2 & 10 \\
\hline Total & 100 & 45 & 35 & 20 & 100 \\
\hline
\end{tabular}


Table 2. T-test statistics of difference in Pre and Post Test Score of the samples of respondents exposed to goal setting skills and the control group

\begin{tabular}{|c|c|c|c|c|c|c|c|c|c|}
\hline \multirow[t]{2}{*}{ Gropus } & \multicolumn{2}{|c|}{ Pre-test } & \multicolumn{2}{|c|}{ Post-test } & \multirow[b]{2}{*}{ Mean Diff } & \multirow[b]{2}{*}{ df } & \multirow[b]{2}{*}{ t-cal } & \multirow[b]{2}{*}{ t-critical } & \multirow[b]{2}{*}{$\mathbf{N}$} \\
\hline & $M$ & $S D$ & $M$ & & & & & & \\
\hline $\begin{array}{l}\text { Intervention } \\
\text { (Goal Setting Skills) }\end{array}$ & 54.08 & 7.75 & 68.25 & 3.95 & 14.17 & \multirow[t]{2}{*}{78} & \multirow{2}{*}{13.30} & \multirow{2}{*}{2.00} & \multirow[t]{2}{*}{40} \\
\hline Control Group & 51.20 & 7.97 & 51.98 & 6.64 & .78 & & & & \\
\hline
\end{tabular}

Significant at .05

\subsection{Administration of Instruments}

The pre-assessment instruments were initially administered to 147 Senior Secondary School Two students. 80 students who did not perform well after the initial assessment were selected for training intervention. The study was carried out over a period of eight weeks starting. One week for pre-test, and one week for post-test. The actual training intervention was spread over six weeks, starting from $4^{\text {th }}$ Febuary- March $15^{\text {th }} 2013$.

\subsubsection{Intervention Procedure}

The study was carried out in three phases:

- Phase I: Pre-intervention assessment

The researcher administered pre-intervention instruments. The instruments used were Achievement Tests in English Language (ATEL) and Goal-Setting Procedure Instrument (GSPI). All those who scored below 40 on the average of the total scores of the two instruments were deemed to have poor performance in English Language.

\section{- Phase II: Intervention programme}

The training package consisted of goal-setting skills. Participants were exposed to eighty minutes of training and discussion once per week for six consecutive weeks, while the control group received no training intervention. Goal-setting skills training intervention was designed to assist participants to acquire specific skills and direct their efforts towards problem solving and sustenance of improvements. It also helps in focusing attention on the knowledge and expertise needed to effectively accomplish any academic task at hand. Therefore it is meant to train participants to acquire effective goal-setting skills that would improve their performance in English Language. Participants were involved in six sessions consecutively, covering all parts of English Language using the goal-setting strategies and work sheets. Discussion, explanation, demonstration and drilling were based on the following; Concept of goal-setting, skills and special abilities involved in goalsetting, setting motivating and SMART goals, setting goals in writing, making an action plan and sticking to it. Accepting feedback and rewards.

However, the control group was exposed to the training of goal-setting skills, two weeks after the intervention programme to enable them benefit from the intervention that worked from the research.

— Phase III: Post-intervention assessment

At the end of the training programme, the research instruments were re-administered on the participants to determine the effects of the training on them.

\section{RESULTS}

\subsection{Test of Hypothesis}

\subsubsection{Hypothesis 1}

There will be no significant difference in the post-test scores on English Language among participants exposed to goal-setting skills and the control group (Table 2).

From Table 2, the intervention goal-setting skills has a $t$ critical less than .05 which indicates that the test is significant therefore there is significant difference between the pre-test and post-test of goal-setting skills (intervention group). While the control has a t critical greater than .05 which indicates that the test is not significant therefore, there is no significant difference between pre-test and post-test of control. Also, from the mean difference column, it shows that goal-setting skills intervention has an effect on students' performance in English language with mean difference of 14.17 , while the control group has the mean difference of .78, since it was the waiting group and did not receive any training intervention. This indicates that goal-setting training has effect on students' performance in English language.

\subsubsection{Hypothesis 2}

There is no significant gender difference in the post-test scores on English Language among participants exposed to goal-setting skills (Table 3).

Table 3 above shows a calculated t- cal of 2.96 given t critical less than .05 which indicates that the test is significant. From the test, the female and male participants exposed to goal-setting training had a mean difference of 1.88. Thus indicating a significant gender difference among participants.

Table 3. T-test statistics of gender difference in Post Test Score of the sample respondents in English Language

\begin{tabular}{|c|c|c|c|c|c|c|c|}
\hline \multirow[t]{2}{*}{ Groups } & \multicolumn{3}{|c|}{ Post-test Score } & \multirow[b]{2}{*}{ Df } & \multirow[b]{2}{*}{ t-cal } & \multirow[b]{2}{*}{ t-critical } & \multirow[b]{2}{*}{$\mathbf{N}$} \\
\hline & $M$ & $S D$ & Mean Diff & & & & \\
\hline Male & 45.38 & 3.42 & \multirow{2}{*}{1.88} & \multirow{2}{*}{38} & \multirow{2}{*}{2.96} & \multirow{2}{*}{2.00} & \multirow{2}{*}{40} \\
\hline Female & 47.26 & 1.74 & & & & & \\
\hline
\end{tabular}

Significant at .05

\section{DISCUSSION OF FINDINGS}

Evidence from the result presented on Table 2 shows that acquiring goal-setting skills has a significant effect on students' performance in English language. The null hypothesis is therefore rejected. In order word this is a significant influence of goal-setting skills on student's performance in English language 
as writers do. This finding agrees with that of Hayes (1986) that goal-setting would lead to good performance in English Language particularly in essay writing. He goes further to stress that, skilled writer's developed content as well as process goals when writing. The importance of goal-setting is especially apparent in the composing behaviour of professional writers as supported by (Lamb 1997). From these findings, it is obvious that setting a goal is fundamental to a good performance in English language. This is so because, once a goal is set, the student has a direction, he is focused and determined to achieve his goals. The intrinsic drive comes naturally and the student achieves his goals so easily.

The result of two hypotheses presented on Table 3 also revealed that there is significant difference in students' performance between male and female students in English Language. The null hypothesis is therefore rejected. To this, Sadker and Sadker (1994) posited that sitting in the same class room, reading the same text book, listening to the same teacher; boys and girls perceive things in different ways and perform differently. Smith (2007) in support of the above stated that girls perform better than boys in languages, while many male students prefer number, numeration and construction. Fennema and Peterson (1985) proposed that gender differences in achievement was because males learn to become more autonomous learners than females and that these autonomous learning behaviours bring about affective factors which include self-confidence, perceived usefulness of the subject and attribution styles.

In conclusion therefore, goal-setting skills would help in a total refinement and transformation of human thoughts thereby sanitizing the thought process for the enhancement of better performance in English language and adoption of positive attitude in one's ideology and persistence towards achieving a resounding academic success, generally. The study has shown that there is no aspect of English Language that should be considered difficult, so long as the students' can apply goalsetting skills appropriately and effectively and remain focused. Most research works have not considered new learning strategies from the students' personal perceptive.

\section{CONCLUSION/ EDUCATIONAL IMPLICATIONS OF FINDINGS}

Findings from this study will advance knowledge and ascertain the effectiveness and efficiency of goal-setting skills and academic performance of students in English Language. It may also be useful to teachers in developing appropriate teaching materials and procedures for use in class. Policy implementation bodies such as inspectors of schools, curriculum designers, trainers and examination bodies may also find this study useful while considering learners' special needs and problems.

\subsection{Recommendations}

Based on the findings of this study the following recommendations are advanced:

- This research should complement the various efforts of those in the helping professions in gathering numerous remediation techniques for assisting students and also improving teaching methodology used for students' with learning difficulties.

- Teachers should focus on the appropriate strategies to improve students' performance in English Language. They should also be made to undergo refresher courses where they can learn the new technical-know-how of teaching English Language.

- Students' should adopt a positive attitude to their studies by setting SMART goals and pursuing these goals vigorously irrespective of their family background and gender.

- Parents should strive to improve their academic status in order to be able to assist their children with their academic work.

— Experienced and qualified teachers should be employed and well remunerated.

\section{REFERENCES}

Barry, N. H. (2007). Motivating the reluctant student. The American Music Teacher, 56(5), 23-27

Brown, T. C. \& Latham, G. P. (2000, August). The effects of training in verbal self-guidance and goalsetting on team playing behavior. Paper presented at the meeting of the Academy of Management, Toronto, Canada.

Burgess, A. (1991). You've had your time: Being the second part of the confessions of Anthony Burgess. New York: Wedenfeld \& Nicholson.

Chomsky, N. (1975). Reflections on language. New York: Pautheon Books.

Ellis N. C (in press). SLA: The Associative-Cognitive (CREED). In B. Vanpetter \& J. Williams (Eds.), Theories of Second Language Acquisition. An Introduction. Cambridge: Cambridge University Press.

Ellis, R. (1997). The study of second language acquisition. Oxford: Oxford University Press

Fennema, E., \& Peterson, P. (1985). Autonomous learning behavior: a possible explanation of gender-related differences in mathematics. In L. C. Wilkinson \& C. B Marrett (Eds.), Gender related differences in classroom interactions (pp. 17-35). New York: Academic Press. doi: 10.1016/B978-0-12-752075-9.50007-6

Hall, H. K. (1990). A Social-cognitive approach to goal-setting. The mediating effects of achievement goals and perceived ability (Unpublished doctoral dissertation). University of Illinois, USA.

Hayes, M. E. (1986). A study of the relationship between the type of behaviour to be modelled and the model's similarity to the observers. Dissertation Abstracts International, 34, 17-23.

Hopman, M., \& Glynn, T. (1989). The effect of correspondence training on the rate and quality of written expression of four low achieving boys. Educational Psychology, 9(3), 197-213. doi: 10.1080/0144341890090303

Ikegbunam, C. I. (1989). Use of study groups and study skills training on study habits and achievement in English comprehension (Unpublished doctoral thesis) University of Lagos, Lagos, Nigeria.

Ilogu, G. C. (2005). Classroom learning and instruction. Lagos: Mandate Communications Ltd.

Jones, S. \& Myhill, D. (2004). 'Troublesome Boys' and 'Complaint Girls': Gender identity and perceptions of achievement and underachievement. British Journal of Sociology of Education, 25(5), 547-561. doi: 10.1080/0142569042000252044

Lamb, M. E. (1997). Parental behaviours in humans. American Zoologist, 25, 883-894.

Locke, E. A., \& Latham, G. P. (1990). A theory of goal setting and task performance. Englewood Cliffs, NJ: Prentice-Hall.

O’Donnel, N. (2006). Cognitive Perspectives on Peer Learning. New York: Alison King.

Ridley, D. S. (1992). Self-regulated learning: The interactive influence of metacognitive awareness and goal-setting. Journal of Experimental Education, 60(4), 293-306. doi: 10.1080/00220973.1992.9943867

Sadker, M., \& Sadker D. (1994). Failing at fairness: How American school cheat girls. New York: Macmillan Publishing.

Schunk, D. H., \& Swartz, C. W. (1993). Goals and progress feedback: Effects on self-efficacy and writing achievement. Contemporary Educational Psychology, 18, 337-354. doi: 10.1006/ceps.1993.1024

Sherer, M., Maddox, J. E., Mercentante, B., Prentice-Dum, S., Jacobs, B., \& Roger, R. W. (1982). The self-efficacy scale: Construction and validation. Psychological Reports, 51(1), 663-671. doi: 10.2466/pr0.1982.51.2.663 
Smith, E (2007). Considering the experiences of 'underachieving' and 'overachieving' student'. International Journal of Research and Method in Education. 30(1), 19-32. doi: $10.1080 / 17437270701207702$

Smith, E. (2003). 'Understanding under achievement: an investigation into the differential achievement of secondary school pupils'. British Journal of Sociology. 24(5), 575-586. doi: 10.1080/0142569032000127143

West African Examination Council (WAEC) (2001-2010). Senior school certificate examination (SSCE). English language Chief Examiner's Report. Nigeria.

West African Examination Council (WAEC) (2001-2010). Senior school certificate examination (SSCE) results. Statistics of performance in English Language. Nigeria. 